\title{
POTENCIAL DE USO E QUALIDADE ESTRUTURAL DE DOIS SOLOS CULTIVADOS COM CANA-DE-AÇÚCAR EM GOIANÉSIA (GO) ${ }^{(1)}$
}

\author{
Eduardo da Costa Severiano ${ }^{(2)}$, Geraldo César de Oliveira ${ }^{(3)}$, Nilton \\ Curi $^{(4)}$ \& Moacir de Souza Dias Júnior ${ }^{(5)}$
}

\begin{abstract}
RESUMO
Com a expansão do setor sucroalcooleiro, tanto os solos com poucas limitações como aqueles que apresentam riscos permanentes ao cultivo intensivo tiveram sua vegetação nativa removida e foram incorporados ao processo produtivo. Para isso, a adoção de sistemas de manejo que mantêm a estrutura do solo pode ser a chave para a manutenção da qualidade e sustentabilidade dos agrossistemas canavieiros. Assim, o objetivo deste estudo foi avaliar o potencial de uso para canade-açúcar e a qualidade estrutural de um Cambissolo Háplico Tb distrófico (CXvbd) e um Latossolo Vermelho-Amarelo distrófico (LVAd), no município de Goianésia, GO. Em cada área, realizou-se a classificação das terras quanto à capacidade de uso. Foram coletadas amostras deformadas nas profundidades correspondentes aos horizontes diagnósticos superficiais e subsuperficiais, para caracterização química e físico-hídrica dos solos. Nas profundidades de 0 a 0,05, 0,1 a 0,15 e 0,3 a $0,4 \mathrm{~m}$, foram coletadas amostras indeformadas para determinação da porosidade do solo, da curva de retenção de água, do intervalo hídrico ótimo e da pressão de preconsolidação. O enquadramento dos solos no sistema de capacidade de uso da terra apontou o CXvbd como pertencente à classe IVe, e o LVAd, à classe IIIs. Os resultados das análises dos atributos químicos e físico-hídricos do CXvbd indicaram que o cultivo contínuo com cana-de-açúcar, mesmo com o enquadramento na classe IVe do sistema de capacidade de uso, deve-se à adoção de terraceamento agrícola, além do fato de essa cultura promover pequeno revolvimento do solo e aumentar a cobertura do solo quando colhida crua. O CXvbd apresentou maior disponibilidade
\end{abstract}

\footnotetext{
(1) Projeto financiado pelo Conselho Nacional de Desenvolvimento Científico e Tecnológico (CNPq) e Empresa Jalles Machado SA. Recebido para publicação em maio de 2008 e aprovado em dezembro de 2008.

${ }^{(2)}$ Doutorando em Ciência do Solo, Departamento de Ciência do Solo da Universidade Federal de Lavras - DCS/UFLA. Caixa Postal 37, CEP 37200-000 Lavras (MG). Bolsista do CNPq. E-mail: severianoec@yahoo.com.br

(3) Professor Adjunto, DCS/UFLA. E-mail: geraldooliveira@ufla.br

(4) Professor Titular, DCSUFLA. Bolsista do CNPq. E-mail: niltcuri@ufla.br

${ }^{(5)}$ Professor Associado, DCS/UFLA. Bolsista do CNPq. E-mail: msouzadj@ufla.br
} 
de água para as plantas, o que tende a trazer benefícios à cultura. O LVAd, nas condições de estudo, é mais suscetível à compactação, necessitando da adequação do tráfego de máquinas.

Termos de indexação: Saccharum sp., planejamento conservacionista, capacidade de uso, indicadores físicos do solo.

\section{SUMMARY: USE POTENTIAL AND STRUCTURAL QUALITY OF TWO SOILS UNDER SUGARCANE PRODUCTION IN GOIANÉSIA, GOIÁS STATE, BRAZIL}

With the expansion of the sugar/alcohol sector, the native vegetation was removed from soils with few limitations as well as with great risks for intensive cultivation and the areas incorporated in the production process. Therefore, the adoption of management systems that maintain the soil structure may be a key for the maintenance of the quality and sustainability of sugarcane production systems. The objective of this study was therefore to evaluate the use potential for sugarcane and structural quality of a Dystrophic Haplic Cambisol (CXvbd) (Inceptisol) and Dystrophic Red-Yellow Latosol (LVAd) (Oxisol), in the county of Goianésia, Goiás State. The soils of each area were classified for their use capacity. Disturbed soil samples were collected at depths corresponding to the surface and subsurface diagnostic horizons, for chemical and physical-hydric characterization. Undisturbed samples were collected (from the layers $0-0.05,0.1-0.15$ and $0.3-0.4 \mathrm{~m}$ ) to determine soil porosity, water retention curves, the least limiting water range and preconsolidation pressure. The evaluation of soils by the land use capacity system indicated that CXvbd belongs to class IVe and LVAd to IIIs. Results of the analysis of the chemical and physical-hydric attributes of the CXvbd indicated that a continuous sugar-cane cultivation, despite the classification as IVe in the use potential system, was due to the adoption of agricultural terraces, aside from the fact that the degrees of soil revolving was lower and of soil cover higher, when sugarcane was harvested green The water availability for plants was highest for CXvbd, which tends to be advantageous for crops. In the study conditions, the LVAd was most susceptible to compaction, which requires limitations of machinery traffic.

Index terms: Saccharum sp., conservation planning, use capacity, soil physical indicators.

\section{INTRODUÇÃO}

A necessidade mundial por fontes alternativas de energia coloca o Brasil em posição de destaque em relação à produção de etanol, em razão das condições edafoclimáticas favoráveis ao cultivo da cana-deaçúcar, o que tem levado à expansão geográfica dessa cultura e a impactos ambientais decorrentes do manejo. Se por um lado a queima da cana-de-açúcar traz grandes prejuízos em termos de qualidade do solo (Centurion et al., 2007) e do ar (Campos, 2003), em contrapartida, quando colhida crua, apesar de a ausência da queima promover o acúmulo do material orgânico na superfície do terreno e melhorar a qualidade física e química do solo (Canellas et al., 2003; Souza et al., 2005), o uso de maquinário em condições inadequadas de umidade pode resultar em uma série de alterações das propriedades físicas do solo (Severiano et al., 2008).

Com a grande demanda por novas áreas para a implantação dessa cultura, solos enquadrados como de menor potencial para o cultivo intensivo, como é o caso da maioria dos Cambissolos, estão sendo incorporados ao processo produtivo. Segundo o sistema de classificação da capacidade de uso utilizado no Brasil (Lepsch, 1991), solos pertencentes a essa classe podem apresentar atributos restritivos ao cultivo intensivo relacionados à menor profundidade efetiva, a teores relativamente elevados de silte em relação aos de argila (relação silte/argila igual ou superior a 0,6 ou 0,7 quando textura argilosa ou média, conforme Embrapa, 2006) e à sua posição na paisagem, geralmente em relevos mais movimentados.

Os Cambissolos constituem um grupo bastante heterogêneo em termos de ambiente (Resende et al., 2007). Na região central do Estado de Goiás, onde a canavicultura tem grande importância no setor agrícola, a ocorrência desses solos na paisagem regional é representativa (Embrapa, 1981). Em alguns casos, eles deveriam ser destinados à preservação permanente, tendo em vista a sua vulnerabilidade ao processo erosivo. No entanto, muitas áreas de 
ocorrência desses solos em várias regiões do Brasil já tiveram sua vegetação nativa removida e vêm sendo cultivadas com cana-de-açúcar de forma intensiva há mais de 50 anos (Berner et al., 2007).

Por outro lado, no Cerrado brasileiro, os Latossolos representam o grupamento de solos de maior abrangência, ocupando cerca de 50 \% da área (Macedo, 1996). O elevado grau de intemperismo confere elevada estabilidade da estrutura, o que, aliado à topografia suavizada onde estão inseridos, favorece sobremaneira o seu manejo. Corrigidos quimicamente, esses solos passaram a contribuir significativamente para a produção agropecuária do País. Entretanto, considerando que o aumento do tráfego de máquinas em condições inadequadas de umidade resulta na degradação da estrutura, torna-se necessário o conhecimento do seu potencial de uso, com o auxílio de indicadores de qualidade do solo que possibilitem a predição das alterações no ambiente de crescimento das plantas decorrentes do manejo a que estão sendo submetidas.

Nesse contexto, sistemas de manejo que aliam colheita de cana-crua e rotação de culturas na renovação do canavial contribuem para a manutenção da estrutura do solo e podem ser considerados medidas-chave na manutenção da sustentabilidade dos agrossistemas canavieiros.

A qualidade física pode ser indicada a partir de seus atributos relacionados com a magnitude com que a matriz do solo resiste à deformação e, ainda, com a sua capacidade em fornecer ar e água em proporções adequadas ao pleno crescimento e desenvolvimento das plantas (Singer \& Ewing, 2000). Embora diversos atributos possam ser utilizados como indicadores de qualidade estrutural, há consenso de que esses devem influenciar diretamente a produção das culturas, assim como aqueles que a influenciam indiretamente, a exemplo do intervalo hídrico ótimo (Silva et al., 1994) e das propriedades envolvidas nos estudos da capacidade de suporte de carga do solo (Dias Júnior, 1994).

O presente trabalho objetivou avaliar a qualidade estrutural e o potencial de uso para cana-de-açúcar de um Cambissolo Háplico Tb distrófico e um Latossolo Vermelho-Amarelo distrófico, no município de Goianésia, GO.

\section{MATERIAL E MÉTODOS}

O trabalho foi desenvolvido nas áreas pertencentes à empresa Jalles Machado S.A., no município de Goianésia, microrregião de Ceres, localizada no centro do Estado de Goiás, a $15^{\circ} 10$ ' S de latitude e $49^{\circ} 15^{\prime} \mathrm{W}$ de longitude, com $640 \mathrm{~m}$ de altitude. Segundo Köppen, o clima local é classificado como tropical de savana, quente e úmido, com inverno seco e verão chuvoso (Aw) e média pluvial anual de $1.500 \mathrm{~mm}$.
Na realização deste estudo foi selecionada uma área localizada em relevo ondulado ( $12 \%$ de declividade média), recoberta por um Cambissolo Háplico Tb distrófico textura média (CXvbd), e outra área localizada em relevo plano (3\% de declividade média), recoberta por um Latossolo Vermelho-Amarelo distrófico textura argilosa (LVAd); ambos os solos foram classificados conforme Embrapa (2006) e cultivados com cana-de-açúcar sob condições de canaplanta, isto é, antes do primeiro corte do canavial, em sistema convencional de preparo do solo, com uma aração a 0,25 $\mathrm{m}$ de profundidade e duas gradagens superficiais. Em cada área, realizou-se a descrição morfológica dos perfis, segundo Santos et al. (2005), e a obtenção dos dados para classificação da capacidade de uso das terras foi realizada de forma paramétrica, seguindo o método de Lepsch (1991).

A amostragem foi realizada coletando-se, em cada área, 12 amostras deformadas nas profundidades de 0-0,2 e 0,4-0,6 m (CXvbd) e 0-0,2 e 0,6-0,8 m (LVAd), correspondentes aos horizontes diagnósticos superficiais (Ap) e subsuperficiais (respectivamente, $\mathrm{Bi}$ e Bw). Foram coletadas ainda 24 amostras indeformadas, nas profundidades de $0-0,5,0,1-0,15 \mathrm{e}$ 0,30-0,40 m, sendo esta última localizada abaixo da camada arada do solo. Os pontos de amostragem foram localizados nas entrelinhas da cultura, totalizando 72 amostras.

As amostras deformadas foram utilizadas na determinação da granulometria, por meio do método da pipeta, da densidade de partículas, pelo método do picnômetro, e na caracterização dos óxidos pelo ataque sulfúrico (Quadro 1), do complexo sortivo e da matéria orgânica do solo - todas as determinações conforme método proposto por Embrapa (1997).

As amostras indeformadas foram utilizadas na caracterização físico-hídrica dos solos. $\mathrm{Na}$ determinação das curvas de retenção de água no solo, 12 amostras foram inicialmente saturadas e submetidas às tensões matriciais de $0,2,4,6,10,33$, $60,80,100,500$ e $1.500 \mathrm{kPa}$ (Embrapa, 1997). As demais amostras indeformadas foram equilibradas, por meio de secagem natural a conteúdos de água variando entre 0,14 e $0,38 \mathrm{~m}^{3} \mathrm{~m}^{-3}$, e submetidas inicialmente ao teste de resistência à penetração, conforme Tormena et al. (1998), utilizando-se de um penetrômetro digital de bancada MARCONI, modelo MA 933, com velocidade constante de $100 \mathrm{~mm} \mathrm{~min}^{-1}$. Posteriormente, as amostras foram submetidas ao ensaio de compressão uniaxial (Dias Júnior, 1994), usando um consolidômetro de marca Boart Longyear, cuja aplicação das pressões é feita por ar comprimido. As pressões aplicadas a cada amostra obedeceram à seguinte ordem: 25, 50, 120, 200, 400, 800 e $1.600 \mathrm{KPa}$, sendo cada pressão aplicada até obtenção de $90 \%$ da deformação máxima.

Após a realização dos ensaios, as amostras foram secas em estufa, a $105^{\circ} \mathrm{C}$, por $48 \mathrm{~h}$, para determinação da densidade do solo (Ds). O volume total de poros (VTP) 
Quadro 1. Caracterização química e física de dois solos cultivados com cana-de-açúcar no município de Goianésia, GO

\begin{tabular}{|c|c|c|c|c|c|c|c|c|c|c|c|}
\hline \multirow{2}{*}{ Horizonte $^{(1)}$} & \multirow{2}{*}{ Profundidade } & \multirow{2}{*}{$\operatorname{Dp}^{(2)}$} & \multicolumn{4}{|c|}{ Granulometria $^{(3)}$} & \multicolumn{3}{|c|}{ Ataque sulfúrico } & \multirow{2}{*}{$\mathrm{Ki}^{(4)}$} & \multirow{2}{*}{$\mathbf{K r} \mathbf{r}^{(4)}$} \\
\hline & & & A & $\mathbf{S}$ & $\mathbf{A F}$ & $\mathbf{A G}$ & $\mathrm{SiO}_{2}$ & $\mathrm{Al}_{2} \mathrm{O}_{3}$ & $\mathrm{Fe}_{2} \mathrm{O}_{3}$ & & \\
\hline & $\mathrm{m}$ & $\mathrm{kg} \mathrm{dm}^{-3}$ & & & & - g & & & & & \\
\hline \multicolumn{12}{|c|}{ Cambissolo Háplico Tb distrófico (CXvbd) } \\
\hline $\mathrm{AP}$ & $0-0,2$ & 2,67 & 266 & 206 & 489 & 39 & - & - & - & - & - \\
\hline $\mathrm{Bi}$ & $0,4-0,6$ & 2,68 & 323 & 209 & 434 & 34 & 117 & 152 & 68 & 1,32 & 1,03 \\
\hline \multicolumn{12}{|c|}{ Latossolo Vermelho-Amarelo distrófico (LVAd) } \\
\hline $\mathrm{AP}$ & $0-0,2$ & 2,64 & 301 & 105 & 532 & 62 & - & - & - & - & - \\
\hline $\mathrm{Bw}$ & $0,6-0,8$ & 2,70 & 352 & 132 & 458 & 58 & 128 & 170 & 50 & 1,27 & 1,08 \\
\hline
\end{tabular}

(1) Ap: horizonte A com perturbação de origem antrópica; Bi: horizonte B incipiente; Bw: horizonte B latossólico. ${ }^{(2):}$ Dp: densidade de partículas. ${ }^{(3)} \mathrm{A}$ : argila; $\mathrm{S}$ : silte; $\mathrm{AF}$ : areia fina; AG: areia grossa. ${ }^{(4)} \mathrm{Ki}$ : relação molecular $\mathrm{SiO}_{2}: \mathrm{Al}_{2} \mathrm{O}_{3}$; $\mathrm{Kr}_{2}$ relação molecular $\mathrm{SiO}{ }_{2}$ : $\left(\mathrm{Al}_{2} \mathrm{O}_{3}+\mathrm{Fe}_{2} \mathrm{O}_{3}\right)$.

foi determinado pela expressão: $V T P=(1-D s / D p)$, sendo Ds a densidade do solo e Dp a densidade de partículas. A macroporosidade do solo foi obtida pela diferença entre VTP e microporosidade, sendo esta considerada o conteúdo de água retido à tensão matricial de $6 \mathrm{kPa}$ (Embrapa, 1997).

Para obtenção das curvas características de água do solo, os conteúdos de água no solo $(\theta)$ foram ajustados de acordo com a tensão da água no solo $\left(\psi_{\mathrm{m}}\right)$. A capacidade de campo $\left(\theta_{\mathrm{CC}}\right)$ foi considerada o conteúdo de água no ponto de inflexão da curva (Ferreira \& Marcos, 1983), determinada pela segunda derivada da equação ajustada, construída com base em polinômios cúbicos e trabalhando-se com o logaritmo da tensão (pF) em função do conteúdo de água no solo, conforme Mello et al. (2002).

A seguir, aplicou-se o teste de Scott-Knott a $5 \%$ entre as umidades geradas pela inflexão e as correspondentes a $6 \mathrm{kPa}$; essas últimas foram obtidas ajustando-se o mesmo polinômio cúbico, porém fazendo-se $\theta=f\left(\psi_{m}=6 \mathrm{kPa}\right)$. A água disponível (AD) foi calculada pela seguinte expressão: $A D=\theta_{\mathrm{i}}-\theta_{1500}$, sendo $\mathrm{AD}$ a água disponível $\left(\mathrm{m}^{3} \mathrm{~m}^{-3}\right) ; \theta_{\mathrm{i}}$, o conteúdo de água equivalente à tensão matricial do ponto de inflexão; e $\theta_{1500}$, o conteúdo de água equivalente à tensão matricial de $1.500 \mathrm{kPa}$.

Os valores de resistência à penetração $(\mathrm{RP})$, obtidos em $\mathrm{kgf} \mathrm{cm}^{-2}$, foram multiplicados pelo fator 0,098 , para transformação em $\mathrm{MPa}$. A pressão de preconsolidação $\left(\sigma_{\mathrm{p}}\right)$ foi obtida da curva de compressão do solo, segundo Dias Júnior \& Pierce (1995), e os modelos de capacidade de suporte de carga dos solos foram obtidos ajustando-se a $\sigma_{\mathrm{p}}$ em função de $\theta$, conforme Dias Júnior (1994). As comparações das regressões foram feitas segundo Snedecor \& Cochran (1989).

O Intervalo Hídrico Ótimo (IHO) foi obtido segundo Silva et al. (2002), determinando-se: a porosidade de aeração adequada ao desenvolvimento da cultura $\left(\theta_{\mathrm{PA}}\right)$, obtida pela fórmula: $\theta_{\mathrm{PA}}=(V T P-0,1)$, e os conteúdos de água no solo na capacidade de campo $\left(\theta_{\mathrm{CC}}\right)$, no ponto de murcha permanente $\left(\theta_{\mathrm{PMP}}\right)$, considerado como o conteúdo de água retido à tensão de $1.500 \mathrm{kPa}$, e correspondente à resistência à penetração de $2,5 \mathrm{MPa}$ $\left(\theta_{\mathrm{RP}}\right)$.

Os resultados das análises dos atributos físicohídricos do solo foram submetidos à análise de variância, segundo o delineamento inteiramente casualizado. As comparações das médias foram realizadas pelo teste de Scott-Knott a $5 \%$.

\section{RESULTADOS E DISCUSSÃO}

O enquadramento dos solos no Sistema de Capacidade de Uso da Terra (Lepsch, 1991) apontou o CXvbd como pertencente à classe IVe, o que se deu em razão da declividade do terreno e da presença de erosão laminar severa, enquanto o LVAd foi enquadrado na classe IIIs, por apresentar como principal fator limitante o caráter álico (Quadro 2).

Segundo recomendações desse sistema, solos enquadrados na classe IV são mais indicados para pastagens, mas podem ser suficientemente aptos para certos cultivos ocasionais, seguindo a proporção de um ano de cultivo pra cada quatro a seis de pastagens (Lepsch, 1991). Solos enquadrados na subclasse IVe apresentam severas limitações por erosão, geralmente relacionadas com declividades acentuadas. Em contrapartida, devido ao fato de a cana-de-açúcar suportar cortes sucessivos, promovendo assim um pequeno revolvimento do solo, sendo este realizado apenas na renovação do canavial, e aliando-se a isso o incremento da cobertura do solo quando esta é colhida crua, sugere-se que o CXvbd possa apresentar elevado potencial para o cultivo intensivo com a cultura da cana-de-açúcar, dependendo dos seus atributos. 
Tendo-se em mente a possibilidade de redução das limitações químicas dos solos (Quadro 2) em decorrência de adubações e calagens, os solos apresentam, nas condições atuais, valores de saturação por bases superiores a $50 \%$ na camada cultivada (horizonte Ap) (Quadro 3), o que é considerado por Sousa \& Lobato (2004) como adequado ao crescimento e desenvolvimento da cultura. Segundo esses autores, observa-se que o teor de $\mathrm{P}$ pode ser considerado baixo nos dois solos $\left(<10 \mathrm{mg} \mathrm{dm}^{-3}\right)$, tornando necessária a adubação da cana-soca com esse nutriente. O teor de Kencontra-se adequado no LVAd e alto no CXvbd.

Com relação aos atributos físicos, observam-se pequenas diferenças entre os solos (Quadro 4), o que se deve à semelhança textural entre eles (Quadro 1), uma vez que o fator que impede que o Cambissolo seja classificado como Latossolo é o horizonte B incipiente, cuja espessura é inferior a 0,5 m - mínimo exigido para B latossólico (Embrapa, 2006). Trata-se, portanto, de um Cambissolo resultante da remoção acentuada de material por erosão do antigo Latossolo, que já teve muito maior expressão geográfica na região (Resende et al., 1988).

Por outro lado, a macroporosidade no CXvbd assumiu valores abaixo daquele considerado limitante ao desenvolvimento da cana-de-açúcar $\left(0,10 \mathrm{~m}^{3} \mathrm{~m}^{-3}\right.$, segundo Centurion et al., 2007) na profundidade de 0,3 a $0,4 \mathrm{~m}$. Salienta-se que a ausência de revolvimento do solo nessa profundidade preservou os atributos físicos naturais desse solo. Em estudo com Cambissolos da região de Campos da Mantiqueira, em MG, Oliveira et al. (1994) salientaram que em condições naturais a baixa macroporosidade desses solos foi o fator responsável pela baixa infiltração de água e pela elevada suscetibilidade deles ao processo erosivo.

A redução da macroporosidade do Cambissolo na profundidade de 0,3 a $0,4 \mathrm{~m}$ deve-se ao incremento no teor de argila (Quadro 1), uma vez que a porosidade total não diferenciou entre as profundidades avaliadas. Esse incremento das frações finas na composição granulométrica eleva o potencial matricial e a retenção de água, resultando no aumento da microporosidade.

A macroporosidade relativamente mais elevada dos solos nas camadas superficiais é resultante da desagregação provocada pelas operações de preparo do solo e dos teores mais elevados de matéria orgânica (Quadro 3). Salienta-se que o tráfego de máquinas para o transporte das mudas durante a implantação do canavial pode ter promovido compactação subsuperficial no LVAd, sendo visualizada pelo incremento na Ds e redução da porosidade à profundidade de $0,1 \mathrm{a} 0,15 \mathrm{~m}$,

Quadro 2. Estrutura do solo, fatores limitantes ao manejo e classificação das terras no sistema de capacidade de uso para dois solos cultivados com cana-de-açúcar no município de Goianésia, GO

\begin{tabular}{|c|c|c|c|c|c|c|c|c|c|c|}
\hline \multirow{2}{*}{ Solo } & \multicolumn{3}{|c|}{ Estrutura $^{(1)}$} & \multicolumn{6}{|c|}{ Fator Limitante ${ }^{(2)}$} & \multirow{2}{*}{$\begin{array}{c}\text { Classe de } \\
\text { capacidade } \\
\text { de uso }\end{array}$} \\
\hline & Tipo & Classe & Grau & $\begin{array}{l}\text { Prof. } \\
\text { efetiva }\end{array}$ & Textura & Permeabilidade & Declividade & Erosão & Específico & \\
\hline & & & & $\mathrm{m}$ & & & $\%$ & & & \\
\hline CXvbd & $\begin{array}{c}\text { Blocos } \\
\text { subangulares }\end{array}$ & Média & Moderado & 0,6 & $\begin{array}{l}\text { Franco } \\
\text { argilo - } \\
\text { arenosa }\end{array}$ & $\begin{array}{l}\text { Rápida/ } \\
\text { Moderada }\end{array}$ & 12 & $\begin{array}{c}\text { Laminar } \\
\text { severa }\end{array}$ & Distrofismo & $\mathrm{IVe}$ \\
\hline LVAd & Granular & $\begin{array}{c}\text { Muito } \\
\text { pequena }\end{array}$ & Forte & $>2,0$ & Argilosa & $\begin{array}{l}\text { Rápida/ } \\
\text { Rápida }\end{array}$ & 3 & $\begin{array}{c}\text { Laminar } \\
\text { ligeira }\end{array}$ & Álico & IIIs \\
\hline
\end{tabular}

(1) Segundo critérios propostos por Santos et al. (2005). ${ }^{(2)}$ Conforme Lepsch (1991).

Quadro 3. Complexo sortivo e teores de matéria orgânica (MO) para dois solos cultivados com cana-deaçúcar no município de Goianésia, GO

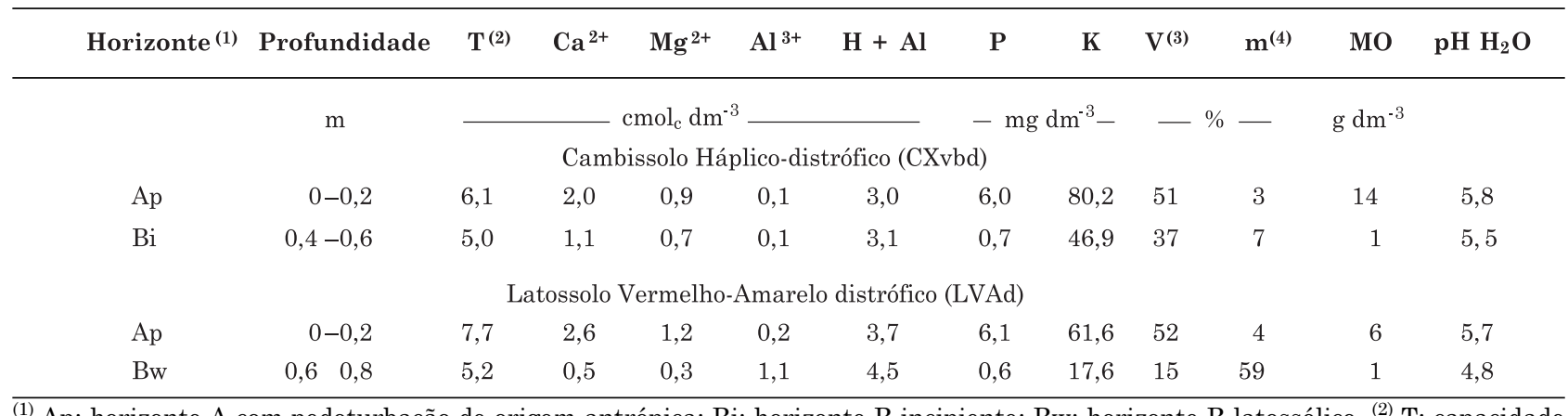

(1) Ap: horizonte A com pedoturbação de origem antrópica; Bi: horizonte B incipiente; Bw: horizonte B latossólico. ${ }^{(2)}$ T: capacidade de troca catiônica $(\mathrm{pH} 7,0) .{ }^{(3)}$ Saturação por bases. ${ }^{(4)}$ Saturação por alumínio. Os valores representam média de 12 repetições. 
Quadro 4. Atributos físicos em três profundidades do Latossolo Vermelho-Amarelo distrófico (LVAd) e do Cambissolo Háplico Tb distrófico (CXvbd), cultivados com cana-de-açúcar, no município de Goianésia, GO' $^{(1)}$

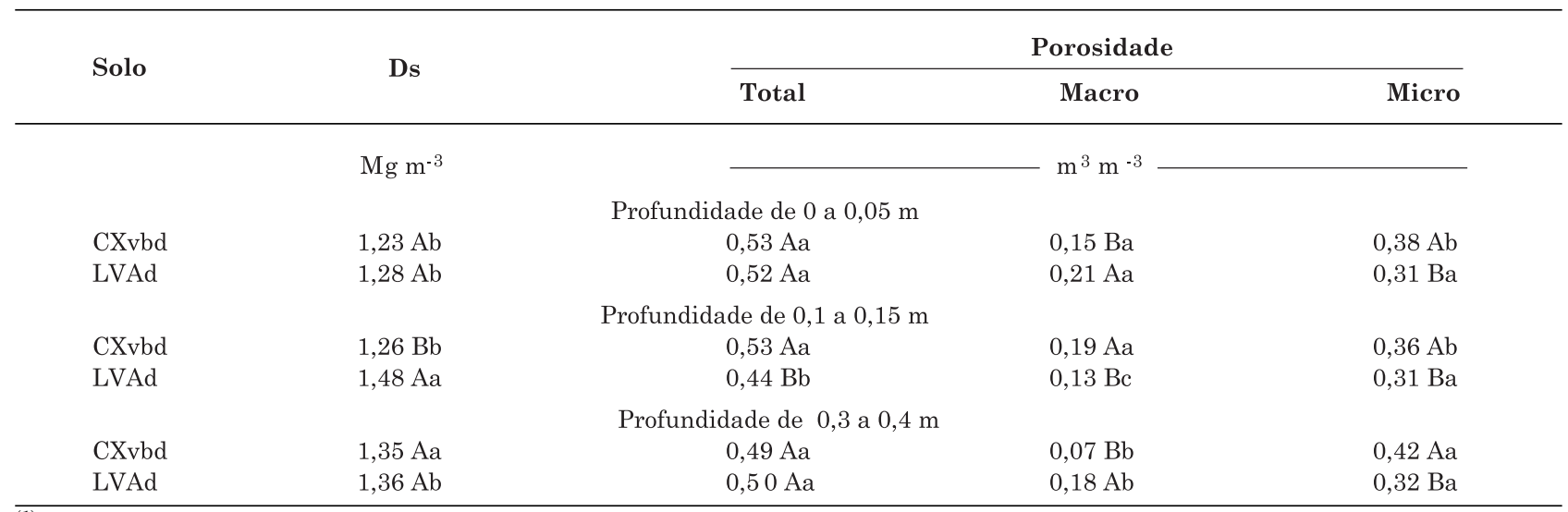

(1) Para cada profundidade, médias seguidas das mesmas letras maiúsculas, nas colunas, não diferem entre si pelo teste de ScottKnott a $5 \%$. Para cada solo, independentemente da profundidade, médias seguidas das mesmas letras minúsculas não diferem entre si pelo teste de Scott-Knott a $5 \%$; Ds: densidade do solo. Valores representam média de 12 repetições.

demonstrando a transmissão de carga nas profundidades subsuperficiais nesse solo. Esses resultados indicam essa profundidade como a de maior suscetibilidade à compactação nesse Latossolo, corroborando estudo de Suzuki et al. (2008), enquanto no CXvbd não foi observada essa diferença.

Observa-se, pela análise das curvas características de água no solo, maior retenção de água no CXvbd em todas as profundidades para a faixa considerada de água disponível (Figura 1), o que, segundo Jaccoud \& Castro (1976), se deve ao maior ajuste entre e dentro dos agregados, promovido pela sua estrutura pedológica do tipo blocos, em comparação à estrutura granular do LVAd (Quadro 2), levando ao aumento das tensões de água no solo no primeiro caso.

Esse fato, confirmado por observações de campo, promove melhores condições para o crescimento e desenvolvimento da cultura durante períodos de veranico e, ainda, promove maior disponibilidade hídrica no início da estação seca, fazendo com que a cultura nessas condições sofra com o déficit hídrico muito depois, em comparação com as áreas de Latossolos. Essa característica do Cambissolo em estudo, detectada pelos agricultores ainda que de forma empírica, impulsionou as explorações canavieiras nos Cambissolos da região, onde o recobrimento da paisagem com esses solos é representativo, conforme apontado no levantamento de solos realizado pela Embrapa (1981).

A determinação do ponto de inflexão da curva característica de água no solo mostra que, para o LVAd, a tensão de água no solo $\left(\psi_{\mathrm{mi}}\right)$ se situa próximo a $6 \mathrm{kPa}$ em todas as profundidades (Quadro 5). Observa-se ainda que os conteúdos de água no solo não diferiram entre o valor no ponto de inflexão $\left(\theta_{\mathrm{i}}\right) \mathrm{e}$ a $6 \mathrm{kPa}\left(\theta_{6 \mathrm{kPa}}\right)$, corroborando os resultados encontrados por Mello et al. (2002), que consideram essa tensão para a determinação do conteúdo de água na capacidade de campo dos Latossolos.

O CXvbd, por sua vez, apresentou maiores valores de tensão nesse ponto em relação ao LVAd, ocorrendo incremento à medida que aumenta a profundidade do solo, com maiores diferenças entre os conteúdos

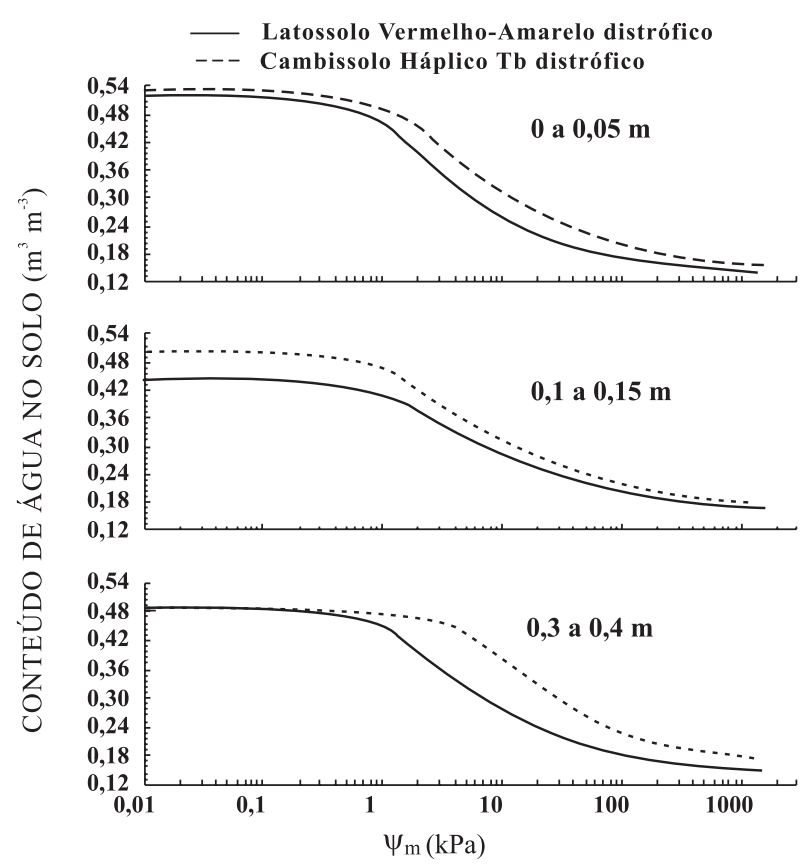

Figura 1. Curva característica de água [conteúdo de água no solo (U) em função do potencial matricial $\left.\left(\psi_{\mathrm{m}}\right)\right]$ no Cambissolo Háplico Tb distrófico (CXvbd) e no Latossolo VermelhoAmarelo distrófico (LVAd) nas profundidades de 0 a $0,05,0,1$ a 0,15 e 0,3 a $0,4 \mathrm{~m}$, cultivados com cana-de-açúcar, no município de Goianésia, GO. 
avaliados na profundidade de 0,3-0,4 m. Esse comportamento deve-se a fatores relacionados com a estrutura do solo, já discutidos, o que tende a promover incremento no potencial matricial desse solo.

Segundo Silva et al. (2002), o manejo do solo promove alterações em vários atributos físicos, os quais interagem entre si, com consequente alteração no ambiente de crescimento das plantas. Considerando que, além dos conteúdos de água no solo na capacidade de campo e no ponto de murcha permanente, a disponibilidade hídrica do solo para as plantas é

Quadro 5. Tensão de água no solo correspondente ao ponto de inflexão da curva característica de água no solo $\left(\psi_{\mathrm{mi}}\right)$, conteúdo de água no solo nesse ponto $\left(\theta_{\mathrm{i}}\right)$ e à tensão de $6 \mathrm{kPa}\left(\theta_{6 \mathrm{kPa}}\right)$, em três profundidades do Latossolo Vermelho-Amarelo distrófico (LVAd) e do Cambissolo Háplico Tb dstrófico (CXvbd), no município de Goianésia, $\mathrm{GO}^{(1)}$

\begin{tabular}{|c|c|c|c|}
\hline Solo & $\Psi_{\mathrm{mi}}$ & $\theta_{\mathbf{i}}$ & $\theta 6 \mathrm{kPa}$ \\
\hline & $\mathrm{kPa}$ & 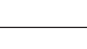 & - \\
\hline & \multicolumn{3}{|c|}{ Profundidade de 0 a $0,05 \mathrm{~m}$} \\
\hline LVAd & 4,3 & $0,33 \mathrm{a}$ & $0,31 \mathrm{a}$ \\
\hline \multirow[t]{2}{*}{ CXvbd } & 6,9 & $0,37 \mathrm{a}$ & $0,38 \mathrm{a}$ \\
\hline & \multicolumn{3}{|c|}{ Profundidade de 0,1 a $0,15 \mathrm{~m}$} \\
\hline LVAd & 6,4 & $0,31 \mathrm{a}$ & $0,31 \mathrm{a}$ \\
\hline \multirow[t]{2}{*}{ CXvbd } & 8,4 & $0,34 \mathrm{a}$ & $0,36 \mathrm{a}$ \\
\hline & \multicolumn{3}{|c|}{ Profundidade de 0,3 a $0,40 \mathrm{~m}$} \\
\hline LVAd & 5,1 & $0,33 \mathrm{a}$ & $0,32 \mathrm{a}$ \\
\hline CXvbd & 20,4 & $0,33 \mathrm{~b}$ & $0,42 \mathrm{a}$ \\
\hline
\end{tabular}

(1) Para cada solo e profundidade, médias seguidas das mesmas letras minúsculas, nas linhas, não diferem entre si pelo teste de Scott-Knott a $5 \%$. Valores representam média de 12 repetições. influenciada pela disponibilidade de $\mathrm{O}_{2}$ e pela resistência mecânica ao sistema radicular, também foi determinado o intervalo hídrico ótimo (IHO) (Figura 2).

Nas profundidades de 0 a 0,05 e 0,1 a 0,15 m do CXvbd e em todas as profundidades avaliadas no LVAd, os limites superior e inferior de água disponível no solo foram de $\theta_{\mathrm{CC}}$ e $\theta_{\mathrm{PMP}}$, respectivamente, o que reflete a boa qualidade física desses solos nessas profundidades após o revolvimento (Silva et al., 2002). Na profundidade de 0,3-0,4 m do CXvbd, o intervalo de água disponível é alterado, já que a resistência à penetração assume valor limitante $\left(\theta_{\mathrm{RP}}\right)$ estando o solo sob baixo conteúdo de água, o que pode ser sintoma de adensamento nesse solo (Figura 2a). Nessas condições, seriam esperadas restrições em termos de aeração do solo $\left(\theta_{\mathrm{PA}}\right)$, o que não ocorreu em razão de a sua textura média favorecer maior aeração, uma vez que, nesse caso, parte da microporosidade do solo (microporos com diâmetro entre 15 e $50 \mu \mathrm{m}$ ) é ocupada com ar, quando o solo se encontrar em sua capacidade de campo.

Em termos de disponibilidade hídrica para a cultura, observa-se pelo comportamento do intervalo hídrico ótimo (Figura 2) uma superioridade do CXvbd nas profundidades de 0 a 0,05 e 0,1 a 0,15 m. Quanto à profundidade de 0,3 a $0,4 \mathrm{~m}$, os solos têm comportamento semelhante. Portanto, a caracterização físicohídrica do solo realizada por meio do IHO subsidia observações de campo realizadas por técnicos do setor sucroalcooleiro da região, de que os efeitos da sazonalidade climática na cultura da cana-de-açúcar são amenizados em áreas de Cambissolo.

Entre os fatores de produção relacionados com a modernização da agricultura, destaca-se o crescimento da demanda pela mecanização, fazendo-se necessário o conhecimento da capacidade de suporte de carga do

\section{CONTEÚDO DE ÁGUA NO SOLO, $\mathrm{m}^{3} \mathrm{~m}^{-3}$}
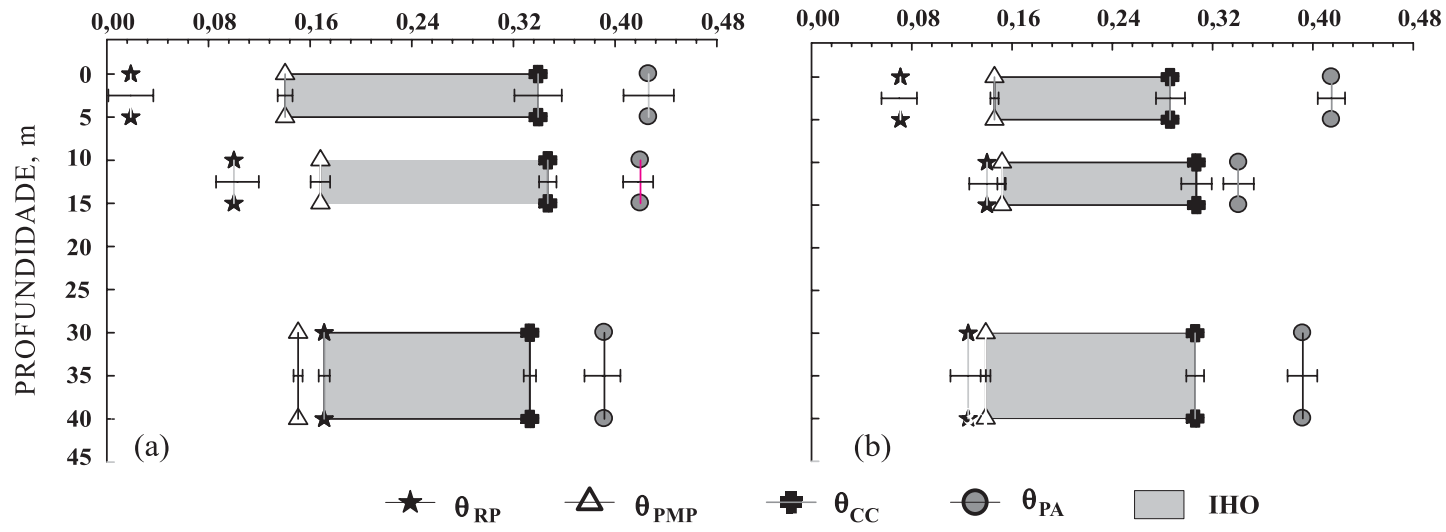

Figura 2. Variação do conteúdo de água no solo $\left(\theta, \mathrm{m}^{3} \mathrm{~m}^{-3}\right)$ para os limites críticos de ponto de resistência do solo à penetração $\left(\theta_{\mathrm{RP}}\right)$, ponto de murcha permanente $\left(\theta_{\mathrm{PMP}}\right)$, capacidade de campo $\left(\theta_{\mathrm{CC}}\right)$ e porosidade de aeração $\left(\theta_{\mathrm{PA}}\right)$, nas profundidades de 0 a $0,05,0,1$ a 0,15 e 0,3 a $0,4 \mathrm{~m}$ do Cambissolo Háplico Tb distrófico (CXvbd) (A) e do Latossolo Vermelho-Amarelo distrófico (LVAd) (B). IHO: intervalo hídrico ótimo. 
solo para minimizar os efeitos do tráfego de máquinas, que levam à sua compactação (Raper, 2005). Os procedimentos estatísticos de Snedecor \& Cochran (1989) não apontaram diferenças de comportamento compressivo nas profundidades de 0 a 0,05 e 0,1 a $0,15 \mathrm{~m}$ do CXvbd (Figura 3). Esse comportamento pode ser explicado pela uniformidade dos atributos físicos desse solo nessas profundidades (Quadro 4) e pela sua influência na pressão de preconsolidação (Oliveira et al., 2003).

Por outro lado, mesmo apresentando maior capacidade de suporte de carga na profundidade de 0,1 a 0,15 m, em relação à camada superficial, o que se deve ao incremento na Ds (Quadro 4), observa-se maior suscetibilidade à compactação do LVAd em todos os conteúdos de água no solo e profundidades avaliadas, o que é influenciado pela sua estrutura granular, enquanto no CXvbd a estrutura em blocos (Quadro 2) confere a esse solo maior resistência à compactação (Severiano et al., 2008).
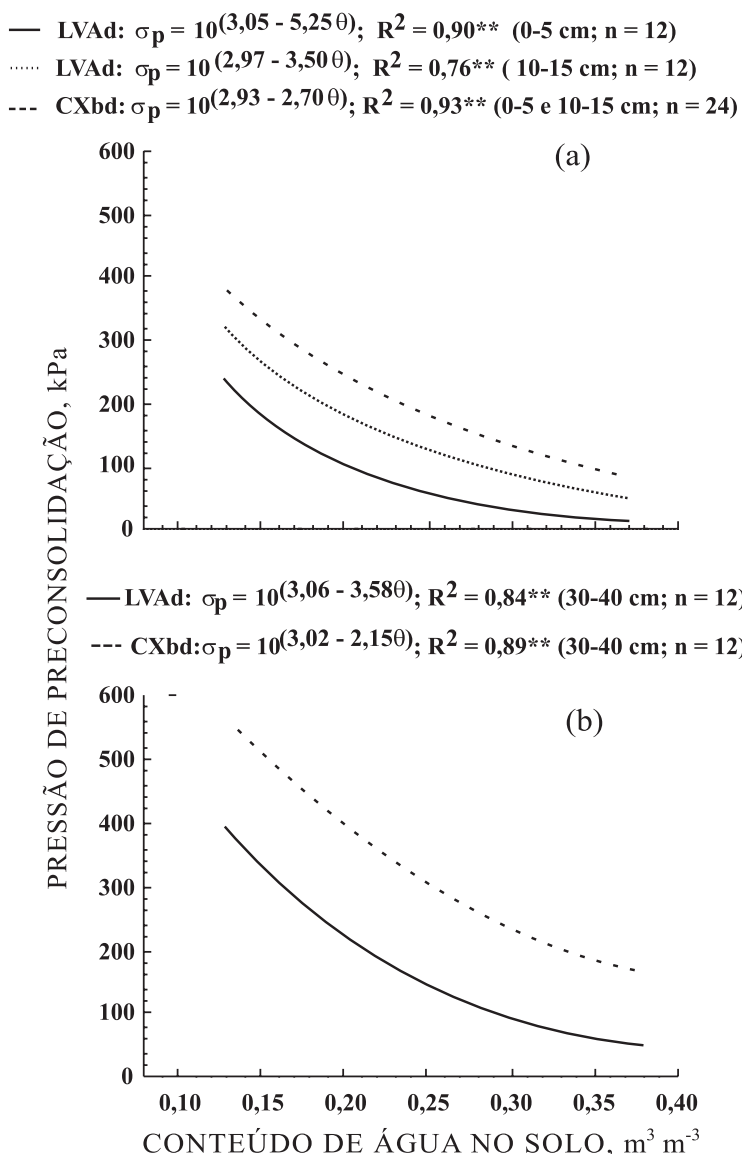

Figura 3. Modelos de capacidade de suporte de carga [variação de pressão de preconsolidação $\left(\sigma_{\mathrm{p}}\right) \mathrm{em}$ função do conteúdo de água no solo] do Latossolo Vermelho-Amarelo distrófico (LVAd) e do Cambissolo Háplico Tb distrófico (CXvbd), nas profundidades de 0 a $0,05,0,1$ a 0,15 e 0,3 a 0,4 m, no município de Goianésia, GO.
Considerando pressões de até $326 \mathrm{kPa}$ como os valores médios aplicados aos solos pelas máquinas utilizadas na colheita da cana-de-açúcar (Severiano, 2007), verifica-se a possibilidade da ocorrência de compactação do LVAd mesmo sob baixos conteúdos de água do solo, impondo mais cautela na tomada de decisão do momento mais adequado para a realização de operações mecanizadas, uma vez que a capacidade de suporte de carga do solo pode ser excedida (Kondo \& Dias Júnior, 1999).

Para a profundidade de 0,3 a $0,4 \mathrm{~m}$, onde não houve ação dos implementos de preparo do solo, os valores de $\sigma_{\mathrm{p}}$ foram superiores àqueles encontrados nas camadas mais superficiais. Entretanto, por ocasião da colheita mecanizada da cana-de-açúcar, quando são utilizados equipamentos que aplicam altas pressões ao solo, mesmo nessa profundidade existe a possibilidade de ocorrer compactação adicional, caso esta seja realizada sob conteúdos mais elevados de água no solo (Alakukku et al., 2003; Raper, 2005).

O conhecimento da capacidade de suporte de carga do solo pode auxiliar no planejamento das atividades durante a safra canavieira, de modo que possibilite as operações mecanizadas em épocas em que os efeitos dessas operações sejam minimizados. Enquanto o CXvbd teria esses efeitos minimizados, quando submetido às operações mecanizadas sob conteúdos mais elevados de água no solo, o LVAd poderia sofrer alterações estruturais mesmo quando mecanizado sob conteúdos mais baixos de água no solo. Esses resultados indicam a possibilidade de cultivo do CXvbd com variedades de cana-de-açúcar que alcancem a maturação em épocas de safra, quando o solo se encontra em condições de conteúdos mais elevados de água no solo, como é o caso da colheita no final do período chuvoso (março/abril). Por sua vez, o LVAd deveria ser cultivado com variedades cujo ponto de maturação coincida com a estação seca.

Em adição, verifica-se que, embora o CXvbd apresente limitações para o uso intensivo com a canade-açúcar de acordo com o sistema de capacidade de uso utilizado no Brasil (Quadro 2), ele apresenta bom potencial de exploração em termos de disponibilidade hídrica e capacidade de suporte de carga. Salienta-se que esse sistema de classificação de terras apresenta maior potencialidade de utilização sob o enfoque conservacionista (Resende et al., 2007), o que é compreensível, haja vista a geralmente maior declividade e menor profundidade efetiva, resultando em menor tolerância de perdas de solo, no caso do Cambissolo, por erosão hídrica. Por esses motivos, o uso e o manejo desses solos necessitam de cuidados especiais, com adoção de práticas intensivas de controle do processo erosivo, como a manutenção de resíduos na superfície (Lal, 2000), obtido pela adoção do sistema de cana-crua (Souza et al., 2005), além da realização de terraceamento agrícola (Bertoni \& Lombardi Neto, 1999). 


\section{CONCLUSÕES}

1. O cultivo contínuo com cana-de-açúcar no Cambissolo Háplico, mesmo com o enquadramento desse solo na classe IVe do sistema de capacidade de uso das terras utilizado no Brasil, deve-se ao fato de essa cultura promover pequeno revolvimento do solo e aumentar a sua cobertura quando colhida crua.

2. O Latossolo Vermelho-Amarelo nas condições de estudo, em razão de sua estrutura granular, mostrouse mais suscetível à compactação, necessitando de adequação no tráfego de máquinas.

3. O Cambissolo Háplico, devido à sua estrutura em blocos, apresentou maior disponibilidade de água para as plantas em comparação com o Latossolo Vermelho-Amarelo, o que tende a trazer maiores benefícios à cultura.

\section{LITERATURA CITADA}

ALAKUKKU, L.; WEISSKOPF.; CHAMEN, W.C.T.; TIJINK, F.G.J.; van der LINDEN, J.P.; PIRES, S.; SOMMER, C. \& SPOOR, G. Prevention strategies for field trafficinduced subsoil compaction: A review. Part I - Machine/soil interactions. Soil Till. Res., 73:145-160, 2003.

BERTONI, J. \& LOMBARDI NETO, F. Conservação do solo. 4.ed. São Paulo, Ícone, 1999. 355p.

BERNER, P.G.M.; VIEIRA, S.R.; LIMA, E. \& ANJOS, L.H.C. Variabilidade espacial de propriedades físicas e químicas de um Cambissolo sob dois sistemas de manejo de canade-açúcar. R. Bras. Ci. Solo, 31:837-844, 2007.

CAMPOS, D.C. Potencialidade do sistema de colheita sem queima da cana-de-açúcar para o sequestro de carbono. Piracicaba, Escola Superior de Agricultura "Luiz de Queiroz", 2003. 103p. (Tese de Doutorado)

CANELlAS, L.P.; VELLOSO, A.C.X.; MARCIANO, C.R.; RAMALHO, J.F.G.P.; RUMJANEK, V.M.; REZENDE, C.E. \& SANTOS, G.A. Propriedades químicas de um Cambissolo cultivado com cana-de-açúcar, com preservação do palhiço e adição de vinhaça por longo tempo. R. Bras. Ci. Solo, 27:935-944, 2003.

CENTURION, J.F.; FREDDI, O.S.; ARATANI, R.G.; METZNER, A.F.M.; BEUTLER, A.N. \& ANDRIOLI, I. Influência do cultivo da cana-de-açúcar e da mineralogia da fração argila nas propriedades físicas de Latossolos Vermelhos. R. Bras. Ci. Solo, 31:199-209, 2007.

DIAS JÚNIOR, M.S. Compression of three soils under longterm tillage and wheel traffic. East Lansing, Michigan State University. 1994. 114p. (Tese de Doutorado)

DIAS JÚNIOR, M.S. \& PIERCE, F.J. A simple procedure for estimating preconsolidation pressure from soil compression curves. Soil Technol., 8:139-151, 1995.

EMPRESA BRASILEIRA DE PESQUISA AGROPECUÁRIA EMBRAPA. Serviço Nacional de Levantamento e Conservação de Solos. Mapa de Solos do Brasil. Rio de Janeiro, 1981.
EMPRESA BRASILEIRA DE PESQUISA AGROPECUÁRIA EMBRAPA. Centro Nacional de Pesquisas de Solos. Manual de métodos de análises de solo. 2.ed. Brasília, Produção de Informação, 1997. 212p.

EMPRESA BRASILEIRA DE PESQUISA AGROPECUÁRIA EMBRAPA. Centro Nacional de Pesquisa de Solos. Sistema brasileiro de classificação de solos. 2.ed. Brasília, Produção de Informação, 2006. 306p.

FERREIRA, M.M. \& MARCOS, Z.Z. Estimativa da capacidade de campo de Latossolo Roxo distrófico e Regossolo através do ponto de inflexão da curva característica de umidade. Ci. Prática, 7:96-101, 1983.

JACCOUD, A. \& CASTRO, A.F. Curvas de caracterização de umidade de solos da área da Universidade Federal Rural do Rio de Janeiro, município de Itaguaí. Pesq. Agropec. Bras., 11:1-9, 1976.

KONDO, M.K. \& DIAS JÚNIOR, M.S. Compressibilidade de três Latossolos em função da umidade e uso. R. Bras. Ci. Solo, 23:211-218, 1999.

LAL, R. Soil management in the developing countries. Soil Sci., 165:57-72, 2000.

LEPSCH, I.F., Coord. Manual para levantamento utilitário de meio físico e classificação de terras no sistema de capacidade de uso: $4^{\mathrm{a}}$ aproximação. Campinas, Sociedade Brasileira de Ciência do Solo, 1991. 175p.

MACEDO, J. Os solos da região dos Cerrados. In: ALVAREZ V., V.H.; FONTES, L.E.F. \& FONTES, M.P.F., eds. O solo nos grandes domínios morfoclimáticos do Brasil e o desenvolvimento sustentado. Viçosa, 1996. p.135-155.

MELLO, C.R.; OLIVEIRA, G.C.; RESCK, D.V.S.; LIMA, J.M. \& DIAS JÚNIOR, M.S. Estimativa da capacidade de campo baseada no ponto de inflexão da curva característica. Ci. Agrotec. 26:836-841, 2002.

OLIVEIRA, G.C.; FERREIRA, M.M. \& CURI, N. Caracterização físico-hídrica de Cambissolos da microrregião Campos da Mantiqueira (MG). Ci. Prática, 18:341-348, 1994.

OLIVEIRA, G.C.; DIAS JÚNIOR, M.S.; RESCK, D.V.S. \& CURI, N. Alterações estruturais e comportamento compressivo de um Latossolo Vermelho distrófico argiloso sob diferentes sistemas de uso e manejo. Pesq. Agropec. Bras., 38:291-299, 2003.

RAPER, R.L. Agricultural traffic impacts on soil. J. Terramechnol., 42:259-280, 2005.

RESENDE, M.; CURI, N. \& SANTANA, D.P. Pedologia e fertilidade do solo: Interações e aplicações. Brasília, MEC/ ESAL/POTAFOS, 1988. 84p.

RESENDE, M.; CURI, N.; REZENDE, S.B. \& CORRÊA, G.F. Pedologia: Base para distinção de ambientes. 5.ed. Lavras, Universidade Federal de Lavras, 2007. 322p.

SANTOS, R.D.; LEMOS, R.C.; SANTOS, U.G.; KER, J.C. \& ANJOS, L.H.C. Manual de descrição e coleta de solo no campo. 5.ed. Viçosa, MG, Sociedade Brasileira de Ciência do Solo, 2005. 92p. 
SEVERIANO, E.C. Indicadores de qualidade estrutural na avaliação da compactação do solo em decorrência da colheita mecanizada da cana-de-açúcar. Lavras, Universidade Federal de Lavras, 2007. 71p. (Tese de Mestrado)

SEVERIANO, E.C.; OLIVEIRA, G.C.; DIAS JÚNIOR, M.S.; OLIVEIRA, L.F.C. \& CASTRO, M.B. Pressão de preconsolidação e intervalo hídrico ótimo como indicadores de alterações estruturais do solo em decorrência das operações de colheita da cana-de-açúcar. R. Bras. Ci. Solo, 32:1419-1427, 2008.

SILVA, A.P.; KAY, B.D. \& PERFECT, E. Characterization of the least limiting water range. Soil Sci. Soc. Am. J., 58:1775-1781, 1994.

SILVA, A.P.; TORMENA, C.A. \& IMHOFF, S. Intervalo hídrico ótimo. In: MORAES, M.H.; MÜLLER, M.M.L. \& FOLONI, J.S.S. Qualidade física do solo: Métodos de estudo sistemas de preparo e manejo do solo. Jaboticabal, Funep, 2002. p.1-20.
SINGER, M. \& EWING, S. Soil quality. In: SUMMER, M.E., ed. Handbook of soil science. Boca Raton, CRC, 2000. p.271-298.

SNEDECOR, G.W. \& COCHRAN, W.G. Statistical methods. 8.ed. Ames, Iowa State University, 1989. 503p.

SOUSA, D.M.G. \& LOBATO, E. Cerrado: Correção do solo e adubação. 2.ed. Brasília, Embrapa Informação Tecnológica, 2004. 416p.

SOUZA, Z.M.; PRADO, R.M.; PAIXÃO, A.C.S. \& CESARIN, L.G. Sistemas de colheita e manejo da palhada de canade-açúcar. Pesq. Agropec. Bras., 40:271-278, 2005.

SUZUKI, L.E.A.S.; REINERT, D.J.; REICHERT, J.M. \& LIMA, C.L.R. Estimativa da susceptibilidade à compactação e do suporte de carga do solo com base em propriedades físicas de solos do Rio Grande do Sul. R. Bras. Ci. Solo, 32:963973,2008

TORMENA, C.A.; SILVA, A.P. \& LIBARDI, P.L. Caracterização do intervalo hídrico ótimo de um Latossolo Roxo sob plantio direto. R. Bras. Ci. Solo, 22:573-581, 1998. 